\title{
Roles of family dynamics on adherence to highly active antiretroviral therapy among people living with HIV/AIDS at a tertiary hospital in Osogbo, south-west Nigeria
}

\author{
Afolabi BA, Afolabi MO, Afolabi AA, Odewale MA, *Olowookere S A
}

Department of Community Health, Faculty of Clinical Sciences, College of Health Sciences, Obafemi Awolowo University, Ile-Ife, Nigeria

\begin{abstract}
Background: Adherence to highly active antiretroviral therapy (HAART) has been proven to be the only effective treatment for HIV/AIDS worldwide. Good adherence to HAART might require good family support.

Objective: To determine the family dynamics and social support of people living with HIV/AIDS (PLWHA) and its roles on HAART adherence at an ARV treatment clinic in Osogbo, Nigeria

Method: Descriptive cross-sectional study. Consenting PLWHA on HAART were interviewed using pre-tested semistructured questionnaire incorporating Perceived Social Support- Family Scale and Family APGAR. HAART adherence was measured using patient self report.

Results: A total of 379 PLWHA were interviewed. Their mean age was 40.8 (SD=9.9) years. Most (60.7\%) were females. More than half (55.7\%) were currently married and the majority (72.1\%) had secondary education and were Yoruba (86.3\%). Most respondents (95.5\%) were adherent to HAART. Over $90 \%$ were satisfied with support received from their family while $82.3 \%$ were treated like other family members. Most attributed their HAART adherence to the care and support received from their family.
\end{abstract}

Conclusion: Most PLWHA had good social support and were adherent to HAART.

Key words: Family dynamics; HAART adherence; Nigeria

African Health Sciences 2013; 13(4): 920 - 926 http://dx.doi.org/10.4314/ahs.v13i4.9

\section{Introduction}

Globally, the pandemic of HIV/AIDS has continued to pose serious health and socio-economic challenges. ${ }^{1}$ By the end of 2010, about 33.3 million persons were estimated to be infected with HIV globally. Of these, 22.5 million were in sub-Saharan Africa, and about 2.98 million in Nigeria., 2,3 Thus, Nigeria has the second highest number of people living with HIV/AIDS (PLWHA) in Africa after South Africa. ${ }^{1,2}$

The World Health Organization characterized the family as the primary social agent in the promotion of health and well being ${ }^{4}$. The family is the natural and fundamental unit of society. Most people are born into a family, live much of their lives within a family, and consider it to be a high priority in their

*Corresponding author:
Dr Samuel A Olowookere
Department of Community Health
Faculty of Clinical Sciences, College of Health
Sciences
Obafemi Awolowo University
Ile-Ife, Nigeria
Email: sanuolowookere@yahoo.com

value system. A healthy lifestyle is usually developed, maintained, or changed within the family context., ${ }^{5,6}$ Multi-drug resistance usually arises from suboptimal HIV treatment adherence. ${ }^{7,8}$ Hence PLWHA on highly active antiretroviral therapy (HAART) should have at least 95\% adherence rate to prevent drug resistance. ${ }^{8,9}$

HIV/AIDS is a highly stigmatizing disease with PLWHA experiencing rejection even by their families; however with availability of treatment, $\mathrm{HIV} / \mathrm{AIDS}$ is now a chronic manageable illness in our society. ${ }^{10-12} \mathrm{~A}$ study on medication adherence to antiretroviral therapy among PLWHA in Nepal reported that people living in extended families were more likely to be non-adherent to therapy compared to people in nuclear families..$^{13}$ Also, money and the need to attend social functions such as marriage, funerals or festivals had been reported by patients for missing an appointment partially or completely. Therefore financial and socio-cultural barriers emerged as themes for missing hospital appointment. Also, patients had shared that they did not want to take their tablets in front of anyone including family members because of fear of stigmatization, 
indicating that socio-cultural barriers affected ART adherence ${ }^{13,14}$.

Hitherto, there have been very few studies on family influence on adherence to antiretroviral drugs at the study site since inception of the antiretroviral programme. Hence the need for this study which determined the influence of family dynamics on adherence to antiretroviral therapy among adult PLWHA in Osogbo, Nigeria.

\section{Methods}

\section{Study site}

Ladoke Akintola University Teaching Hospital was established by the Oyo State and Osun State in 2001. It is located in Osogbo capital of Osun State, Southwestern Nigeria. The hospital offers a spectrum of clinical, surgical and laboratory services that include diverse areas such as Family medicine, General outpatients care, Antenatal and postnatal care, preventive and social medicine, General surgery, Orthopaedics, Psychiatry, Pediatrics and Internal medicine.

The antiretroviral treatment centre was established in July, 2007 by the Institute of Human Virology, Nigeria with the support of the Federal Government of Nigeria. It provides comprehensive HIV/AIDS care for people living in Osun State and beyond. Though, antiretroviral drugs are supplied free from the Federal Government, beneficiaries are expected to undergo mandatory free laboratory investigations before commencement of the medication which includes CD 4 count, Liver function test, Chest X-ray and blood chemistry. The antiretroviral (ART) clinic opens on Tuesdays and Thursdays from 8 am to $4 \mathrm{pm}$ with emergency care provided on 24 hour basis. Patients are seen monthly for drug refill and psycho-social counseling.

This study population included adult patients living with HIV/AIDS on antiretroviral drugs in ART clinic of Ladoke Akintola University Teaching Hospital, Osogbo, Osun State.

\section{Study design}

This is a descriptive, cross-sectional, hospital-based study of patients attending antiretroviral (ART) clinics of Ladoke Akintola University Teaching Hospital, Oshogbo. The study was conducted over a period of six months from October 2008- March 2009.

\section{Sample size calculation}

The required sample size of 327 was calculated using a formula for estimating the minimum sample size

African Health Sciences Vol 13 Issue 4 December 2013 in descriptive health studies $\left[\mathrm{n}=\mathrm{Z}^{2} \mathrm{pq} / \mathrm{d}^{2}\right]^{13}$ and finding from a previous study ${ }^{14}$ where $54 \%$ were reported. The minimum sample size was increased by $10 \%$ to take care of incomplete/non response and refusals.

\section{Sampling method}

Participants were serially recruited into the study over a 6 month period. Inclusion criteria were consenting PLWHA on antiretroviral therapy for at least three months while very ill PLWHA and those who were unable to provide information were excluded.

\section{Data collection and analysis}

Data were collected using a pre-tested, semistructured, interviewer-administered questionnaire that has socio-demographic data, family characteristics, perception of family support using Perceived Social Support Family Scale and perception of family functioning using Family APGAR Scales.

The Perceived Social Support-Family Scale (PSS-Fa) PSS-Fa is a 20-item validated measure of family support. Subject answered "yes", "no" or "don't know" to questions on their feelings and experiences with their family. Each response that leads to family support was scored 1 while response indicating lack of family support was scored 0 . Summated scores were used to arrive at a family support score for each subject, with a possible score range of 0 to 20 points. Higher scores indicated higher level of perceived family support with scores equal to or greater than 11 taken as strong family support, scores 7 to 10 taken as weak family support while scores equal or less than 6 taken as no family support). The Perceived Social Support - Family Scale has been found to have good reliability and validity. The original Perceived Social Support Scale has an alpha coefficient of 0.90 indicating that the scale has excellent internal consistency. The alpha for the PSSFa ranged from 0.88 to $0.91 .{ }^{15}$

Family APGAR is acronyms for adaptability, partnership, growth, affection and resolve. It is a 5 item validated measure of family functioning with subject answered "hardly ever", "sometimes" or "almost always" based on their frequency of feeling satisfied. "Hardly ever" received a score of 0 , "sometimes" a score of 1 and "almost always" a score of 2 . The total score range from 0 to 10 with higher scores indicated higher degree of satisfaction with family functioning. Score of less than 6 was taken as family dysfunction while 6 to 10 was normal family function. The Family APGAR has good 
reliability and validity. The Cronbach's alpha values reported across studies using Family APGAR have ranged from .80 to .85 , and item-to-total correlations ranged from .50 to $.65^{16,17}$.

The survey instrument was available in English but translated to Yoruba to accommodate for non English speaking respondents and was completed either before or after the physicians visit, in a separate consulting room, on individual basis, in respect of patients' privacy. Measure of adherence used was self report and pharmacy pill counting. Information obtained included duration of commencement of antiretroviral drugs, attendance at follow up clinic, numbers of drugs being taken, drug régime, cost and source of drugs.

The level of adherence of the PLWHA to antiretroviral was calculated from the formula: \% adherence over 7 days $=$

(No of pills taken - No of pills missed) x 100

No of pills taken

A score of $95 \%$ and above represented good adherence and less than 95\% was rated poor adherence. ${ }^{7,8}$

Quantitative data were analyzed using SPSS for Windows software version 14. Descriptive and chisquare statistical tests were employed. A probability value less than 0.05 was accepted as being statistically significant.

\section{Ethical Clearance}

Ethical clearance was obtained from the Research and Ethics Committee of Ladoke Akintola
University Teaching hospital, Osogbo. Informed written consent was obtained from each participant before the interview.

\section{Results}

A total of 379 PLWHA were interviewed. Their mean age was 40.8 years ( $S D=9.9$, range $20-70)$. There were $149(39.3 \%)$ males and $230(60.7 \%)$ females. Majority were married (55.7\%) while $22.1 \%$ were divorced. Most completed secondary education $(72.1 \%)$ and were Yoruba (86.3\%). Most respondents $(95.5 \%)$ were adherent to HAART.

Table 1 showed the relationship between sociodemographic characteristics and HAART adherence of respondents. There was no significant relationship between sociodemographic characteristics and adherence to HAART $(\mathrm{p}>0.05)$. Mean score for the family APGAR was 7.82(SD=2.31) while for the PSS-Fa was $10.37(\mathrm{SD}=2.42)$.

Most respondents were cared for by their spouse $(53.3 \%)$ and parents $(29.6 \%)$ (figure 1$)$.

About 93\% were satisfied with care received from their family while $82.3 \%$ were treated like other family members (table 2).

Majority (99\%) of adherent PLWHA had normal family APGAR score compared with $1 \%$ non adherent PLWHA ( $p=0.023$ ) while $97 \%$ of adherent PLWHA had strong perceived social support compared with 3\% non-adherent PLWHA ( $\mathrm{p}=0.001$ ) (table 3).

Table 1: Relationship between socio-demographic characteristics and HAART adherence among PLWHA at LAUTECH teaching hospital Osogbo, Nigeria

\begin{tabular}{llll}
\hline Socio demographic characteristics & $\begin{array}{l}\text { Good adherence } \\
(>\mathbf{9 5} \%)\end{array}$ & $\begin{array}{l}\text { Poor adherence } \\
(<\mathbf{9 5} \%)\end{array}$ & $\mathbf{X}^{2} ; \mathbf{d f} ;$ p-value \\
\hline $\begin{array}{l}\text { Age group } \\
20-29\end{array}$ & $46(95.8 \%)$ & $2(4.2 \%)$ & \\
$30-39$ & $126(94.7 \%)$ & $7(5.3 \%)$ & \\
$40-49$ & $123(94.6 \%)$ & $7(5.4 \%)$ & \\
50 and above & $67(98.5 \%)$ & $1(1.5 \%)$ & Fisher's $\mathrm{p}=0.6255$ \\
Gender & $141(94.6 \%)$ & $221(96.1 \%)$ & \\
Male & $9(3.9 \%)$ & $8(5.4 \%)$ & $\mathrm{X}^{2}=0.447 \mathrm{df}=1 \mathrm{p}=0.504$ \\
Female & & & \\
Highest level of education & $108(94.7 \%)$ & $6(5.3 \%)$ & \\
Tertiary & $154(96.9 \%)$ & $5(3.1 \%)$ & \\
Secondary & $61(93.8 \%)$ & $4(6.2 \%)$ & \\
Primary & $39(95.1 \%)$ & $2(4.9 \%)$ & Fisher's $\mathrm{p}=0.6654$ \\
No Formal Education & & & \\
\hline
\end{tabular}


Continuation of table 1

\begin{tabular}{|c|c|c|c|}
\hline Socio demographic characteristics & $\begin{array}{l}\text { Good adherence } \\
(>95 \%)\end{array}$ & $\begin{array}{l}\text { Poor adherence } \\
(<95 \%)\end{array}$ & $\mathrm{X}^{2} ; \mathrm{df} ; \mathrm{p}$-value \\
\hline \multicolumn{4}{|l|}{ Marital status } \\
\hline Single & $44(95.7)$ & $2(4.3)$ & \\
\hline Married & $201(95.3)$ & $10(4.7)$ & \\
\hline Divorced & $81(96.4)$ & $3(3.6)$ & \\
\hline Widowed & $36(94.7)$ & $2(5.3)$ & Fisher's $\mathrm{p}=0.9579$ \\
\hline \multicolumn{4}{|l|}{ Occupation } \\
\hline Civil Servant & $95(95.0 \%)$ & $5(5.0 \%)$ & \\
\hline Trader & $197(96.1 \%$ & $8(3.9 \%)$ & \\
\hline Artisan & $70(94.6 \%)$ & $4(5.4 \%)$ & Fisher's $\mathrm{p}=0.7982$ \\
\hline \multicolumn{4}{|l|}{ Religious affiliation } \\
\hline Christianity & $174(94.6 \%)$ & $10(5.4 \%)$ & \\
\hline Islam & $176(96.7 \%)$ & $6(3.3 \%)$ & \\
\hline Traditional & $14(93.3 \%)$ & $1(6.7 \%)$ & Fisher's $\mathrm{p}=0.4128$ \\
\hline
\end{tabular}

Table 2: Satisfaction of PLWHA with family caregivers at LAUTECH teaching hospital, Osogbo, Nigeria

\begin{tabular}{lll}
\hline Satisfaction of PLWHA & Frequency & $\mathbf{\%}$ \\
\hline Satisfaction with moral support received from family & & \\
Yes & 331 & 87.3 \\
No & 48 & 12.7 \\
Satisfaction with talking and sharing with family & & \\
Yes & 305 & 80.5 \\
No & 74 & 19.5 \\
Satisfaction with care received & & \\
Yes & 352 & 92.9 \\
No & 27 & 7.1 \\
Satisfaction with relationship with family & 312 & 82.3 \\
Yes & 67 & 17.7 \\
No
\end{tabular}

Table 3: Relationship between family support and HAART adherence of PLWHA at LAUTECH teaching hospital, Osogbo Nigeria

\begin{tabular}{llcr}
\hline Family support & \multicolumn{2}{c}{ HAART adherence } & \\
\cline { 2 - 3 } & Adherent & Not adherent & $\mathrm{X}^{2} ; \mathrm{df} ; \mathrm{p}$ value \\
\hline PSS-Fa & $11(84.6 \%)$ & $7(7.6 \%)$ & \\
None & $2(15.4 \%)$ & $266(97.1 \%)$ & \\
Weak & $85(92.4 \%)$ & $8(2.9 \%)$ & Fisher's $\mathrm{p}=0.0326$ \\
Strong & & & \\
Family APGAR & $54(79.4 \%)$ & $14(20.6 \%)$ & \\
Dysfunction & $308(99 \%)$ & $3(1 \%)$ & Fisher's $\mathrm{p}=0.001$ \\
Normal & & & \\
\hline
\end{tabular}




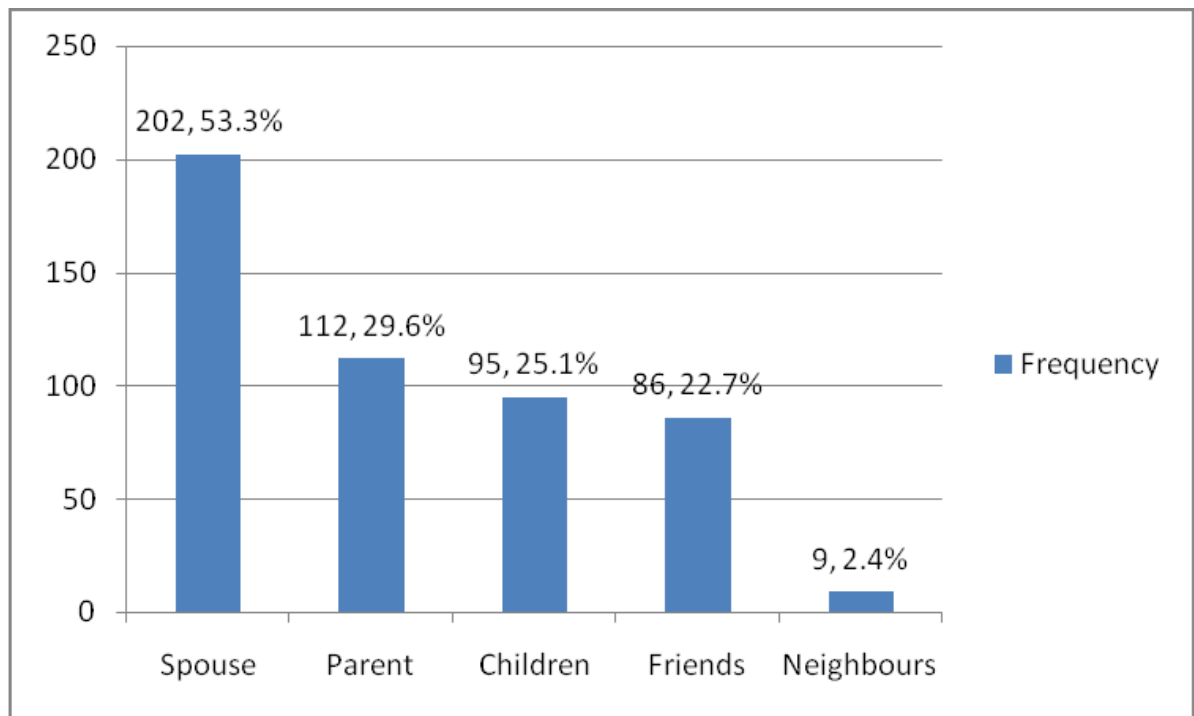

Figure 1: Characteristics of family caregivers of PLWHA at LAUTECH teaching hospital, Osogbo, Nigeria

\section{Discussion}

The study reported a higher adherence level to HAART among the respondents compared with previous studies in southwestern Nigeria. For example, Olowookere et al $(2008)^{10}$ in a study on HAART adherence among PLWHA at Ibadan reported $62.9 \%$ while Afolabi et al (2009) ${ }^{18}$ in another study among PLWHA in Ife-Ijesa zone of Osun state reported $44 \%$. These studies employed similar method, that is patient self report, with this study as well as Olowookere et al $(2008)^{10}$ including pharmacy pick up in estimating adherence rates.

Various adherence studies had reported different reason for non-adherence to HAART. For example, Weiser et al in $2003^{19}$ reported that the principal barriers to HAART adherence included financial constraints (44\%), stigma (15\%), travel/migration $(10 \%)$, and side effects $(9 \%)$ while Olowookere et al $(2008)^{10}$ reported forgetfulness $(55.6 \%)$ and side effects $(35.2 \%)$ as major reasons for non-adherence to HAART. However none of these studies looked at influence of family support on HAART adherence.

This present study showed that family support contributed to the respondent's high drug adherence. This emphasized the importance of involving the family in the care of these patients. Family caregivers are major stakeholders in patient management especially in chronic diseases such as HIV/AIDS and when carried along by the patients and health care workers will enhance patient adherence to drug therapy as reported in this study.
Several studies had shown the importance of the family in providing support for patient's care. ${ }^{20-22}$

The good adherence rate may also be explained by the following factors. Firstly, the clients on antiretroviral therapy at Lautech Teaching Hospital, Osogbo in partnership with Institute of Human Virology, Nigeria access their drugs and laboratory investigations free. Another factor that might have contributed to the relatively high adherence rate among respondents is the nature and quality of support received from the care institution. On-going adherence and psycho-social counseling services were offered to PLWHA on antiretroviral therapy. This study showed that the relatively high adherence rate could be attributed to high moral and psychological support received from family care givers. Infact, most patients were satisfied with care received from their family members. However, some patients reported lack of care and neglect from their family caregivers. This they cited was responsible for their poor drug adherence which resulted from stigma and discrimination they suffered from their family caregivers. Globally, stigma and discrimination are major obstacles leading to reduced treatmentseeking behavior and effective HIV/AIDS prevention and care, especially in sub-Saharan Africa. ${ }^{9,23-26}$ Studies showed that patients often missed their doses as a result of fear of being identified as HIV-positive and being on antiretroviral medications for the rest of their lives. ${ }^{24,25}$ As a result, strategies to address the problem of stigma should be important and necessary components of all adherence 
counseling interventions. ${ }^{22,26}$ This further emphasized the need to educate family caregivers about mode of transmission of HIV/AIDS and how to care for their relatives who live with HIV/AIDS instead of stigmatizing and neglecting them. ${ }^{23,24}$ PLWHA need love and care from their family members, not stigma and neglect. ${ }^{26}$

This paper highlights the importance of family caregivers in improving their HIV positive relative's adherence to antiretroviral therapy while providing necessary HIV/AIDS care to them. The family caregiver while serving as a nonpaid treatment partner could motivate these PLWHA to live positively and enhance their adherence rates. A well informed family caregiver on HIV/AIDS care will not stigmatize or discriminate against their HIV positive relatives. Therefore, findings in this study could be used by policy makers to encourage PLWHA to have treatment partners who could be targeted for HIV care and support training including drug adherence training which will improve their quality of life and adherence rates.

Major limitations of this study included that being a cross-sectional study it is difficult to establish cause-effect relationship while self report as a measurement of adherence relied on patient remembering having taken the drug though pharmacy pickup was equally used to cross-check. Despite assurances on purpose of the study, some respondents may have given socially accepted answers to some sensitive questions.

\section{Conclusion}

PLWHA with good social support were adherent to HAART. There is need to educate and train family caregivers on stigma reduction and how to care and support their HIV positive relatives.

Competing interest: None declared

\section{Reference}

1. UNAIDS HIV epidemic update 2010. Available at http://www.unaids.org. Accessed $12^{\text {th }}$ October, 2011.

2. Federal Ministry of Health of Nigeria. 2010 national HIV seroprevalence sentinel survey among pregnant women attending antenatal clinics in Nigeria. Abuja, Nigeria: Department of Public Health 2011.

3. Federal Ministry of Health of Nigeria.HIV/STI Integrated Biological and Behavioural Surveillance Survey (IBBSS). 2007.
4. World Health Organization: Community Homebased Care in Resource-Limited Settings: A Framework for Action WHO Library Cataloguing-in-Publication Data. Geneva, Switzerland; 2002.

5. Adetunji AA, Ladipo MMA, Irabor AE, Adeleye JO. Perceived family support and blood glucose control in type 2 diabetes. Diabetes International. 2007: 18-9.

6. United Nations General Assembly Resolution 217a (111), 10 December, 1938.

7. Webster RD, Barr D. Adherence to Highly Active Antiretroviral Therapy. A compendium of HAART Adherence Research, November 1997November 1999; 2-17

8. Paterson D. Swindells S, Mohr J, Brester M, Vergis E. How much adherence is enough? A prospective study of adherence to protease inhibitor therapy using MEMS caps. 6th conference on Retroviruses and Opportunistic Infections. Chicago. 1999. [Abstract \# 92].

9. Monjok E, Smesny A, Okokon I.B, Mgbere O, Essien E.J. Adherence to antiretroviral therapy in Nigeria: an overview of research studies and implication for policy and practice. HIV/AIDS - Res Palliative Care. 2010; 2: 69-76

10. Olowookere S.A, Fatiregun A.A, Akinyemi J.O, Bamgboye A.E, Osagbemi G.K. Prevalence and determinants of nonadherence to highly active antiretroviral therapy among people living with HIV/AIDS in Ibadan, Nigeria. J Infect Dev Ctries 2008; 2(5):369-72.

11. Ncama BP: Models of Community/HomeBased Care for People Living With HIV/AIDS in Southern Africa. JANAC 2005; 16(3):33-40.

12. Gaborone Declaration on Community Homebased Care. First Regional (SADC) Conference on Community Home Based Care. Gaborone, Botswana 2001.

13. Sharma S, Khadga P, Dhungana GP, Chitrakar U. Medication Adherence to Antiretroviral Therapy Among Patients Visiting Antiretroviral Therapy Center at Tribhuvan University Teaching Hospital, Kathmandu, Nepal. Kathmandu Univ Med J 2013; 41(1):50-3.

14. Joglekar N, Paranjape R, Jain R, Rahane G, Potdar R, Reddy KS, Sahay S. Barriers to ART adherence $\&$ follow ups among patients attending ART centres in Maharashtra, India. Indian J Med Res December 2011; 134: 954-9 
15. Kish L. Survey sampling. John Wiley and Sons, N.Y. 1965.

16. Sheri W, William W, David B. Barriers to antiretroviral adherence for patients living with HIV infection and AIDS in Botswana. AIDS. 2003; 34(3):73-7.

17. Procidano ME, Heller K. Measures of perceived social support from friends and from family: Three validation studies. J Community Psychol 1983; 11:1-24.

18. Smilkstein, G. The Family APGAR: A proposal for family function test and its use by physicians. Journal of Family Practice. 1978; 6(6): 1231-9.

19. Smilkstein G, Ashworth C, Montano D. Validity and reliability of the Family APGAR as a test of family function. Journal of Family Practice. 1982; 15: 303-11.

20. Afolabi MO, Ijadunola KT, Fatusi AO, Olasode OA. Determinants of adherence to antiretroviral drugs among people living with HIV/AIDS in the Ife-Ijesa of Osun State, Nigeria. Afr J Prm Health Care Fam Med. 2009:1(1), Art. \#6, 6 pages. DOI: 10.4102/phcfm. v1i1.6. Available at: http:/ /www.phcfm.org Accessed 18 $8^{\text {th }}$ October 2011

21. Weiser S, Wolfe W, Bangsberg D, Thior I, Gilbert P, Makhema J, Kebaabetswe P, Dickenson D, Mompati K, Essex M, Marlink R. Barriers to antiretroviral adherence for patients living with HIV infection and AIDS in Botswana. $J$ Acquir Immune Defic Syndr. 2003; 34(3): 281-8.
22. Makoea M.G Jubber K. Confidentiality or continuity? Family caregiver' experiences with care for HIV/AIDS patients in home-based care in Lesotho. SAHARA J. 2008; 5 (1): 36-46

23. Adeyemi E.O. HIV/AIDS and family support systems: A situation analysis of people living with HIV/AIDS in Lagos. SAHARA J. 2007; 4 (3): 668-77

24. Holzemer WL, Uys LR. Managing AIDS stigma. SAHARA J. 2004; 1(3): 165-74

25. Vanable PA, Carey MP, Blaire DC, Littlewood RA. Impact of HIV related stigma on health behaviors and psychological adjustment among HIV-positive men and women. AIDS Behav 2006; 10:473-82.

26. Mbonu CN, van den Borne B, De Vries NK. Stigma of People with HIV/AIDS in SubSaharan Africa: A Literature Review. Journal of Tropical Medicine. 2009, Article ID 145891, doi:10.1155/2009/145891

27. Rao D, Kekwaletswe TC, Hosek S, Martinez J, Rodrigez F. Stigma and social barriers to medication adherence with urban youth living with HIV. AIDS Care 2007; 19: 28-33.

28. Ware NC, Wyatt MA, Tugenberg T. Social relationships, stigma and adherence to antiretroviral therapy for HIV/AIDS. AIDS Care 2006; 18: 904-10 